S Research Square

\title{
Vertical Program of Screenings and Check-ups in the Russian Federation: Design, Implementation and Lessons Learnt
}

\section{Igor Sheiman ( $\square$ isheiman@hse.ru )}

National Research University Higher School of Economics Faculty of World Economy and International Affairs: Nacional'nyj issledovatel'skij universitet Vyssaa skola ekonomiki Fakul'tet mirovoj ekonomiki i mirovoj politiki https://orcid.org/0000-0002-5238-4187

\section{Sergey Shishkin}

National Research University Higher School of Economics International College of Economics and Finance: Nacional'nyj issledovatel'skij universitet Vyssaa skola ekonomiki Mezdunarodnyj institut ekonomiki i finansov

\section{Svetlana Sazhina}

National Research University Higher School of Economics: Nacional'nyj issledovatel'skij universitet Vyssaa skola ekonomiki

\section{Research Article}

Keywords: Vertical health program, screenings, public health, Russian Federation

Posted Date: December 22nd, 2021

DOI: https://doi.org/10.21203/rs.3.rs-1169567/v1

License: (9) This work is licensed under a Creative Commons Attribution 4.0 International License. Read Full License

Version of Record: A version of this preprint was published at Archives of Public Health on April 15th, 2022. See the published version at https://doi.org/10.1186/s13690-022-00878-3. 


\section{Abstract}

Background. The Russian Federation has introduced a vertical large-scale program of 'dispensarization' (Program) that includes health check-ups and screenings for the entire adult population. It is expected to improve the results of medical interventions and ensure health gains at a relatively low cost. The major research question: Does the design and implementation of the program meet the expectations?

Methods. We analyze regulatory acts and the literature on the design and the outcomes of the Program. Physicians' surveys and interviews are conducted to understand the capacity of primary care providers to meet the requirements of the Program, as well as the link between the early identification of new illnesses and their follow-up management, administration of the program, the barriers to its successful implementation.

Results. There is a substantial progress of the coverage of the population and increase in the number of identified illnesses. Some specific instruments of the Program implementation work well, others require more careful design and additional integrative and managerial activities. The capacity of primary care providers does not allow to provide high quality preventive services, as well as to ensure a continuum of preventive and curative work. The pattern of the Program administration facilitates its nation-wide implementation according to the unified rules, but makes it more difficult to account for the local conditions and limits the autonomy of professionals to choose specific population risk groups and a list of services. The interaction of providers in preventive activities is inadequate.

Conclusion The expectations of the Program are too high due to the inconsistency in its design and implementation. The major lesson learnt is that the program like this should meet the capacity of primary care and be designed as a complex of interrelated activities to identify illnesses and provide their followup management.

\section{Background}

The majority of European countries have implemented comprehensive approaches to public health. Population-based check-ups and screenings have become an important instrument of the early identification of illnesses and their follow-up management. These activities are usually viewed as a way to improve the chances of survival for people living with cancer and other illnesses by ensuring that health services can focus on diagnosing and treating the disease earlier [1]. The population coverage by screenings is high and growing in many OECD countries [2].

The impact of these activities on health outcomes is not as easy as it might seem. It depends on the selection of preventive services, as well as on the implementation practices in the specific national context. There is a substantial body of literature on the justification of screening programs. Wilson and Jungner [3] set out ten principles of the choice of screenings, which remain the cornerstone of the literature on this issue, particularly the principle that the ratio of cost/utility should not be lower for screenings than for the curative activities. Numerous studies evaluate the expected impact of these 
programs on mortality and other health indicators, as well as the expected cost effectiveness of the alternative programs $[4,5,6]$. There is a growing consensus on the principle of selecting the program: 'Screening may bring benefits but also harm; just because it can be done does not mean that it should be done' [7].

Another body of literature addresses the design and organization of screening programs. WHO Regional Office for Europe [8] suggests core steps of screening pathway from identifying target populations to monitoring and evaluation. The major research areas include the ways individuals in the target population are identified, forms of their involvement, the appropriate management of screen positive and negative results, actors of service provision and their interaction [9].

Practically all these studies address the developments in Western countries. Much less attention is paid to the post-Soviet countries. Some of them have deeply rooted traditions of the population-based preventive campaigns. Modern Russia inherited the Semashko model, which had declared the priority of preventive activities. But their implementation after the dissolution of the USSR has been limited by chronic underfunding of health system. Public funding does not exceed 3.5\% GDP over the last three decades [10]. In the early 2010s, the priority of prevention campaigns has been re-vitalized in the form of a nation-wide vertical program of 'dispensarization' (further Program), that is a set of preventive activities, including health check-ups and screenings. This is a term from the original Semashko model, practically unknown in the international literature.

The expectations of the Program are very high in Russia. The official attitude is that the early detection of ill health will allow to improve the results of medical interventions and ensure health gains at a relatively low cost. The Federal Ministry of Health $(\mathrm{MoH})$ estimates the contribution of the prevention campaign to 'keeping people healthy' at the level of $60 \%$ [11]. Also, the Program is viewed as a tool that will decrease the need for curative work of primary care providers. The $\mathrm{MoH}$ predictes a fall of curative visits share from 60 to $40 \%$ of all primary care physicians visits with a corresponding increase in the share of preventive visits [12]. Such optimistic expectations explain a substantial involvement of the government in the implementation of the Program.

The Program design provides for the specific instruments of its implementation - highly centralized administration, a universal set of services to identify illnesses among centrally determined target groups, methods of planning, reporting, monitoring, etc. Some of these instruments, for example, provision of preventive services in multi-specialty primary care settings, a large-scale promotion campaign, the establishment of special units responsible for this work, are not common internationally.

The recently implemented policies to strengthen health prevention in Russia have prompted a number of questions: Does the design and implementation of the Program meet the capacity of the current health system? Do specific Russian instruments really work? Does a highly centralized pattern of the Program administration facilitate or complicate its successful implementation? Which lessons can be learnt from this Program for other the countries? Addressing these questions may be of interest to health policy makers in other countries seeking the ways to improve public health. We explore these questions by 
reviewing the design of the Program, studying its implementation practices and discussing the results in the context of domestic and international developments in public health. The selection of specific checkups and screenings is not discussed in the paper, since it is country-specific and is beyond our research questions.

The motivation to produce this paper is to encourage a more careful study of population-based prevention programs, particularly in countries with limited financial resources for health care. Their policy makers often seek ways to solve health care problems through the early identification of new illnesses. The major message is that this activity does not automatically yield health gain. The population-based programs of check-ups and screenings should meet the capacity of primary health care. They should be designed as a complex of interrelated activities to identify illnesses and provide a follow-up management of chronic cases. Physicians should have a discretion regarding the choice of prevention patterns, including the coverage of specific population risk groups and a list of check-ups and screenings. A close interaction of providers in the course of new diseases identification is also needed.

\section{Methods}

To explore the objectives and the design of the Program, we analyzed the regulatory acts of the government and the domestic literature on the subject, including the reports in limited circulation, unpublished documents, memorandums, and presentations from our personal collections. The literature on the similar programs in other countries was searched in the MEDLINE data base using the query "screening", "health check-up", "public health programs". All findings were checked manually and around $30 \%$ were relevant.

The implementation of the Program was studied with the focus on:

- the adequacy of the capacity of primary care providers to implement the Program;

- the link between the early identification of new illnesses and their follow-up management in multispecialty primary care settings;

- interactions between providers of preventive services (district physicians, public health workers and specialists) in terms of the flow of information on the early identification of new illnesses;

- the way the Program is administered in multi-specialty primary care settings;

- comparison of official and physicians' estimates of the Program coverage.

The practices of the Program implementation were explored using a physicians survey. It was conducted online in April-May 2019 through the mobile ap "Handbook of Physician" (available in Google Play and AppStore) with 540 thousand of registered users. We randomly selected 1103 physicians and feldshers (paramedics) who were directly involved in provision of preventive services in primary care settings under the Program, including district therapists (63.2\% of respondents), outpatient specialists (18.7\%), general practitioners (9.9\%), paramedical personnel (8\%). They represent most of regions (81 out of 85 regions of the country) and the structure of population residence (658 physicians from regional centers, 172 - other 
urban areas, 273 - from rural areas). A questionnaire with 25 questions on the above mentioned dimensions of implementation practices was sent to the selected group of respondents.

To understand the degree of professional autonomy on the choice of target population groups and specific preventive services, we conducted 103 face-to-face interviews with primary care physicians and outpatient specialists in three big multi-specialty urban polyclinics in Moscow city and Moscow oblast (the region around the capital) in January 2020 when Covid-19 pandemic had not affected the work of primary care yet. We explored the way preventive activities were planned, reimbursed and administered in polyclinics. Each physician whom we approached directly responded to 10 questions.

We also conducted face-to-face interviews with two high-level managers of private medical companies that were involved in the realization of the Program. The main interview topics were: What is the estimate of the actual coverage by the program?"; "Can primary care physicians select population groups and their own ways to conduct health check-ups|?"; "Does centralized administration of the Program facilitate or complicate its successful implementation?" "What is needed to ensure a follow-up management of patients with the early identified diseases?" The interview data were compared with the results of public opinion surveys conducted by polling companies.

The analysis of the Program outcomes is based on the indicators of the population coverage and the number of identified new diseases at various stages. Official data of the federal Ministry of health and $\mathrm{MHI}$ Fund were compared with the informal estimates of physicians.

No single aspect of the research would be sufficiently robust on its own, but the combination of literature and regulatory acts analysis, physician survey, face-to-face interviews, national public opinion surveys and statistical analyses create a rich picture of how the Program is designed and implemented, what are the barriers to achieving positive outcomes.

\section{Objectives And Design Of The Program}

The regulatory document of the Federal Ministry of Health [13] defines the dispensarization as 'a complex of activities that includes health check-ups and additional methods of investigations conducted with the aim of evaluating health status... of targeted groups of population'. The Program pathway is similar to the one recommended by WHO for screening programs: identification of the population eligible for screening, invitation and information, testing, referrals to specialists, diagnosis, follow-up management of identified cases, reporting the outcomes [7]. Most of these steps are in place in the Program, except for the follow-up management. The latter is mentioned in the regulatory act as a so called 'dynamic dispensary surveillance'. This term of the original Semashko model means that every identified case of a serious disease is subject to a certain set of clinical protocols (which is close to the modern programs of chronic disease management). However, the follow-up management of the case does not constitute a component of the Program. One of its objective is formulated as 'establishing the group of dispensary surveillance of patients with chronic diseases and high risks of circulatory system diseases, that is 
determining the need for such a surveillance rather than its actual provision. Three health groups of the population are determined according to the severity of identified illnesses.

Thus, the Program is viewed as the way to ensure the early identification of illnesses and prevention of their complication. The dispensarization process for an individual is finalized with a documentation of medical examination results, assigning to a health group and some awareness of health problems.

A set of preventive activities is based on the evidence of their outcomes collected by research institutions. A universal set of these activities and the pattern of their provision are determined for the entire country. The process of dispensarization for an individual patient consists of two stages. The first stage is aimed to detect risk factors and deviations in a patient's health. The second stage is to confirm or reject the first stage findings. Patients are referred to specialists for consultation and/or additional tests. These services are provided to the target age and sex groups of population. People older than 40 years in all regions of the country are supposed to go through a required set of check-ups and screenings once a year. The group of 18-39 years old - once in three years. Most of children go through only the stage of check-ups.

The design of the Program is based on the assumption that most preventive activities are provided in the same outpatient setting - a multi-specialty polyclinic with 10-15 categories of outpatient specialists in big urban areas, 3-5 categories in small cities and the number of people served ranging from 30 to 300 thousand people. The major providers of the first stage activities for adults are district therapists and GPs, for children - district pediatricians (together they are further referred to as district physicians DPs). In big polyclinics, they are reinforced by the staff of a preventive unit - physicians and nurses responsible only for preventive activities. Such units exist in practically all urban polyclinics [14]. Specialists deal with the second stage of the Program. Rural and small town areas are served mostly by solo practices (physician ambulatories). They take on preventive activities of the first stage and refer patients to urban polyclinics for the second stage activities. Feldshers do this work in the smallest rural areas.

Planning and reporting are based on the federal regulation. The major indicator is the coverage of the eligible citizens. It is planned vertically - for the entire country, regions, communities, medical organizations, district units served by DPs. Also, the Federal Program of state guarantees of free medical care - the major health planning and funding document - sets the targets for the number of physician visits with the "preventive aim" and their unit cost. Using these targets, regions plan their own volumes of preventive care with the following distribution of these volumes across communities and polyclinics. The major reporting indicators include the coverage of the population and the incidence of detected cases of circulatory system diseases and cancer.

Monitoring the Program follows the lines of planning and reporting. In addition to the aggregate information, detailed data is collected: the number of specific services, detected illnesses, incidence of risk factors, the number of patients who need a dynamic dispensary surveillance, health groups and their structure. 
Preventive services under the Program are reimbursed by regional mandatory health insurance $(\mathrm{MHI})$ funds. The rates of payment are set for a so called 'finished case of dispensarization', that is a fixed package of services determined by the regulation for the first stage of the Program. A 'luft' of $15 \%$ of the number of services is allowed, while all screenings are obligatory. A bundled payment for the first stage is supplemented with a fee-for-service reimbursement of additional consultations and tests at the second stage. The control of the actual number of 'finished cases' is conducted by health insurers - mostly private entities that are involved in $\mathrm{MHI}$. In addition to this amount, polyclinics receive a small bonus (around 13-15 USD) for each identified new oncological case [15]. The amount of polyclinics funding under the Program is linked to the planned volume of preventive activities. If the actual volume is lower, then the amount of funding is lower than planned. The idea behind this pattern of funding is to promote preventive activities.

\section{Results: Empirical Evidence Of The Program Implementation 4.1. What is the primary care capacity to implement the Program?}

The Program has been implemented in the health system where DPs have been overburdened with a curative work. The survey indicates that $63.9 \%$ of district therapists serve more adults than a normative load of physician established by the $\mathrm{MoH}-1700$ adults per therapist. $21.7 \%$ of respondents report that they exceed this target nearly by two times.

The average size of the catchment area per district therapist in the country is 2900 adults, while in some regions $-3-4$ thousand [16]. Our estimate of the deficit of district therapists to meet the normative load is $33 \%$, district pediatricians $-19 \%$. Their task profile has increased substantially due to the introduction of the Program.

\subsection{How do providers of preventive services interact?}

Since a number of providers is involved in preventive activities, it is important to explore the issue of their interaction with the focus on the flow of information. The survey indicates that nearly two thirds of respondents (63.8\%) indicate that health check-ups are conducted by DPs, $13 \%$ - by physicians of preventive units, $22.4 \%$ - jointly. Only half of DPs always (32.2\%) or often (18.2\%) receive information about check-up results when they are conducted by preventive units. The rest seldom or never receives it (Fig. 1). This is a sign of a blurring responsibility for check-ups between DPs and preventive units, as well as a poor interaction between them. DPs who manage most of identified cases may lose some information.

Another area of providers' interaction is between DPs and specialists. Every third DP (34.2\%) seldom receives information about the results of the second stage dispensarization, every fourth $(24.3 \%)$ doesn't receive it at all. Thus, more than a half of DPs don't report coordination with specialists involved in the Program. 


\subsection{What is the follow-up management of the identified illnesses?}

As indicated above, the Program provides for the distribution of the eligible population across health groups. This is an important information for district physicians who are responsible for their patient list. But more than half of DPs (53\%) are unaware of the distribution of their patients across health groups. Check-ups and screenings are conducted, patients with health problems are identified, but many physicians responsible for their follow-up management don't know about results of preventive activities.

Not less indicative is an estimate of a quality of the follow-up management of identified illnesses. Only $7.7 \%$ of respondents indicate that a set of actual curative activities meets the requirements of a pattern of dispensary surveillance issued by the Federal Ministry of Health. The majority reports that these requirements are met only for some patients or are not met at all (Fig. 2).

The usual practice to evaluate the outcomes of chronic disease management is to look at the number of disability days, emergency care visits, disease-specific mortality rates [17]. In this research, we tried to explore a trend of these indicators according to the estimates of the respondents. A decrease in the number of disability days of chronic patients is reported by only $14 \%$ of physicians. More than a half of respondents are unaware of the number of emergency calls and hospital admissions of their chronic patients.

These findings are similar to a clinical expertize conducted by the private health insurer 'RosgosstrahMedicina' [18]. The analysis of medical records of 7043 patients after their hospital admissions with a stroke or a myocardial infarction indicates that nearly half of these patients have not seen a doctor during the year prior to admission. The nation-wide survey of physicians in late 2018 demonstrate that $72 \%$ of respondents agree with the point that the Program has not contributed to the management of the identified new diseases [19]

\subsection{How is the Program administered in multi-specialty polyclinics?}

A centralized Program design and administration set a chain of vertically determined rules. Physicians involved in the implementation of the Program work according to the rules determined by their polyclinics' administrators, who in turn follow the commands of the federal and regional health authorities. The following evidence of physicians' limited professional autonomy is collected in face-to-face interviews with physicians of urban multi-specialty polyclinics:

- $66 \%$ of physicians report that they have individual plans of the number of preventive and curative visits, developed by polyclinics administrators. Only $34 \%$ plan their activity themselves;

- $59 \%$ indicate that the failure to implement individual plans on the number of visits may cause reduction in their remuneration; 
- only $25 \%$ of physicians select patients themselves for check-ups and screenings after assessing their risk factors, that is invite those with the highest risks. The majority relies on the centrally determined target population groups.

Administrators of multi-specialty polyclinics plan the number of visits and the Program coverage in the catchment areas, control the activity of physicians. These are the signs of a limited professional autonomy of physicians.

\subsection{Official vs. physicians' estimates of the Program outcomes}

As stated above, the major outcome indicator in the official reporting is the coverage of the eligible population. The Federal Fund of MHI reports that in 2018 92\% of eligible population has actually undergone dispensarization, in $2019-110 \%$ [20].. However, physicians are less optimistic. More than half $(51.4 \%)$ report that this share is less than $60 \%$, while $17.4 \%$ think that the coverage is less than $20 \%$.

We also asked a question 'Why do you think there is a common opinion in the society that the number of people that have actually undergone dispensarization is lower than official estimates?' Nearly two thirds of physicians (62.6\%) report that the major reason for this opinion is that people are reluctant to undergo dispensarization, therefore physicians have to report an upward distortion of the coverage.

Another reporting indicator is the number of identified new illnesses. According to the annual estimates of the $\mathrm{MoH}$, the number of new oncological illnesses identified in the course of dispensarization increased in $2013-2019$ by 2,6 times (from 21.3 to 55 thousand) [21]. Their share in the total amount of new oncological cases increased over this period from 25-36\% [22].

\section{Discussion}

The Program of dispensarization in Russia has raised the priority of the population-based preventive activities. The early identification of illnesses is currently viewed as one of the major areas of health policy. Primary care providers are increasingly focused on delivering check-ups and screenings to identify new cases and this work is financially encouraged by the government. There is a substantial progress of the coverage of the population and the number of identified illnesses. However, the expectation that the Program will substantially improve the results of medical interventions and ensure health gains seems too high.

The empirical evidence indicates that two important components of the screening programs pathway follow-up management of identified cases and monitoring - are poorly represented in the Program. More than half of DPs are unaware of the distribution of their patients across health groups, they don't know the results of check-ups and screenings. The reported coverage and quality of the follow-up management of identified cases are low. 
The revealed interaction of preventive and curative activities does not meet the prevailing conceptual approach based on the assumption that a screening program pathway should include a stage of the follow-up management of the detected illnesses: '...there is no point in offering a screening program if there are insufficient facilities or health personnel to provide treatment for those who need it' [7]. The authors give an example of a mass screening program for thyroid cancer in South Korea in 1999, which led to the number of cases being detected increasing 15 -fold and yet no reduction in mortality from thyroid cancer. In Russia, the Program is focused on the identification of new illnesses. This creates the risks of violating the principle of a continuum of preventive and curative activities. The Program might be less ambitious about the identification of new illnesses but focused on risk groups and include the management of new chronic cases.

Another issue of the Program design and implementation is a gap between its major objective and the capacity of primary care. The gap with resources leaves physicians of polyclinics with two major options. The first is to substitute a usual curative work for check-ups and screenings, which is not easy because of the influx of new cases. The second is to report optimistically about the progress of the Program implementation with an upward distortion of its coverage and to underprovide the follow-up care of the detected cases. The survey indicates that physicians agree with a common opinion that the actual coverage of the Program is much lower than the one reported by health authorities.

The Program uses some specific instruments unknown or uncommon internationally. First, its implementation in urban areas is based on the model of a big multi-specialty polyclinic. The major strength of this model is its capacity to provide comprehensive preventive and curative care. Patients can undergo check-ups and screenings, see DPs and specialists 'under one roof". Also, a polyclinic model is expected to demonstrate the additional leverage to implement integrated care pathways. But to make this happen, specific integrative and managerial activities are needed. There is some evidence that this strength is not fully realized in curative work [23]. Our survey provides the evidence of a poor interaction of physicians in the dispensarization process. More than a half of DPs don't report coordination with specialists.

Another specific instrument is the establishment of preventive units in polyclinics, that have taken on some traditional preventive functions of DPs. This innovation may strengthen the capacity of polyclinics to implement the Program under the condition that professions of preventive units coordinate their work with DPs. Our survey indicates their inadequate interaction with the risk of the violation of the unity of preventive and curative work. Thus, the potential of a preventive unit is not fully used.

Forming population health groups according to the results of the medical examination is also a useful instrument of the Program. It can be used for resource planning. The share of the third group with the lowest health status increased from 44\% in 2013 to $54 \%$ in 2018 [24].

An important instrument of the Program implementation is its support and large-scale promotion by the Government. The opportunities and benefits of preventive activities are widely presented in the state media and official websites with the focus on the information how and where to pass medical 
examination. Private employers are legally required to promote the involvement of their employees and to offer them a day-off once a year to undergo the dispensarization [25]. In some regions, temporal offices for check-ups have been established in popular trade and recreation zones (for example, there were 46 such offices in Moscow city parks in 2019 [26]), as well as in big educational institutions and industrial centers. In addition to the support activities, administrative pressure is used wherever possible. Public servants, teachers, medical workers, students and some other groups of population are strongly recommended to participate in the campaign. There are voices to introduce financial sanctions for those who ignore the Program, including increasing their contribution to mandatory health insurance. All these strategies contribute to the Program coverage. However, physicians tend to think that the population is rather passive in spite of a large-scale promotion of the Program by the government.

A specific instrument is a 'finished case of preventive care' as a provider payment unit, which is designed to motivate providers to offer check-ups and screenings. It really works. The number of preventive checkups of adults increased by 2.1 times over 2012-2018, children - by $25 \%$ [16]. The opposite side of the coin is that this instrument limits the professional autonomy of physicians on the choice of preventive services for an individual. They have to provide the entire bundle of services to be reimbursed, irrespective of the actual need of a patient. Inversely, a necessary test that is not included in the list of the 'finished case' will not be paid. Internationally, fee-for-service, pay for performance and program-based payment are used to promote preventive activities in addition to a capitation method. FFS is used to promote only priority preventive services, while the latter two methods stimulate reaching specified targets - the coverage of a certain population group, a regular work with chronic and multiple cases, decrease in hospital admissions and other targets that reflect an integrated preventive and curative work rather than a delivery of a fixed set of services to identify new illnesses [27, 28].

The role of a highly centralized administration of the Program is controversial. On the one hand, the federal government has initiated it, provided regions with additional funding, made the campaign a priority of health policy. The centralized leverage is needed to involve providers in preventive activities and to control their actual implementation, as well as to promote participation of people in check-ups and screenings.

On the other hand, a highly centralized pattern of the Program design and implementation has a number of drawbacks. Uniform target population groups and a set of preventive activities limit the flexibility of regions in responding to local needs and special conditions - variation in the disease incidence, the capacity of PHC, the most vulnerable population groups. Centrally established indicators of the population coverage, volumes of preventive care and the number of identified illnesses make regional health authorities and PHC providers look for the ways to reach the targets irrespective of the local capacity to treat new cases. The professional autonomy of physicians to select their own patterns of preventive work is limited by a chain of vertically determined rules.

Reporting and monitoring of the Program outcomes follows the logic of the centralized administration and politically loaded campaigns. The federal $\mathrm{MoH}$ makes an emphasis on easily attainable indicators 
and targets so that to ensure and to show the progress. The actual health gains due to the dispensarization are beyond the scope of monitoring. To the best of our knowledge, there are no attempts to assess: a) the impact of specific tests and screenings on the identification of new cases, b) the actual coverage, specific activities and health outcomes of the follow-up dispensary surveillance, $c$ ) the cost of specific preventive services, d) the cost effectiveness of the entire Program and its elements. This is a serious limitation for the Program adjustment to the activities with the highest health gains and cost effectiveness. A virtual absence of a sound measurement and monitoring can hardly be attributed to the lack of qualification. Rather, it is a by-product of a command-and-control governance of the health system.

\section{Conclusion}

The Program of dispensarization has increased the coverage of the population with check-ups and screenings. The Program aims at increasing the number of identified illnesses with a low priority of the follow-up management of new cases. The empirical evidence indicates that the capacity of primary health care does not allow to provide check-ups and screenings, as well as to ensure a continuum of preventive and curative work. A highly centralized pattern of the Program administration facilitates its nation-wide introduction and implementation according to the unified rules, but makes it more difficult to account for local conditions. The balance between centralized governance and the right of regions to adjust the Program to the local conditions has not been reached yet. This is an important task for any large-scale prevention campaign. Some specific instruments work well, particularly the establishment of preventive units in primary care settings, forming health groups of the eligible population, large-scale support and promotion of preventive campaign by the government. Others require more careful design and additional integrative and managerial activities.

The major lesson learnt from this bold experiment is the understanding of insufficiency of a simplistic approach to health care problems by increasing the priority of the early identification of illnesses with the expectation that this may become a 'magic tool' of health improvement. The expectations of the program are too high, but there is a lack of consistency in its design and implementation. The population-based programs of check-ups and screenings should meet the capacity of the health care and be designed as a complex of interrelated activities to identify illnesses and provide their management with the focus on chronic cases.

\section{Abbreviations}

OECD - Organization of Economic Cooperation and Development

WHO - World Health Organization

$\mathrm{MoH}-$ Ministry of Health

Program - program of dispensarization in the Russian Federation 
GP - general practitioner

DP - district physician

$\mathrm{MHI}$ - mandatory health insurance

\section{Declarations}

\section{Ethics approval and consent to participate}

National Research University High School of Economics has a "Commission on the intra university surveys and ethical reviews of empirical research projects" https://www.hse.ru/org/hse/irb/. Projects under the Basic research program do not require an ethics approval statement from this commission. The authors are ready to participate.

\section{Consent for publication}

Nigel Edwards and Igor Sheiman agree to publish the paper "What next of the polyclinic? New models of primary health care are required in many Former Soviet countries".

\section{Availability of data and materials}

The datasets used and analyzed during the current study are available from the corresponding author on reasonable request.

\section{Competing interests}

The authors declare that they have no competing interests.

\section{Funding}

No funding for the paper

\section{Authors' contributions}

Nigel Edwards (NE) participated in the design of the study, collection of literature, writing and reviewing the text. Igor Sheiman (IS) participated in conducting physicians surveys and face-to-face interviews, writing and reviewing the text. All authors read and approved the final manuscript. 


\section{Acknowledgement}

This paper is an output of the research project implemented as a part of the Basic Research Program at the National Research University Higher School of Economics in Moscow, Russian Federation. The authors are grateful to Rowan Dennison and Svetlana Sazhina for a kind assistance.

\section{Author details}

Nigel Edwards Nuffield Trust, Chief Executive, 59 New Cavendish St, London, W1G 7LP, UK nigel.edwards@nuffieldtrust.org.uk

Igor Sheiman (corresponding author) National Research University Higher School of Economics.

Professor of Chair of Health Management and Economics. Moscow, Russian Federation. 10100020 Myasnitskaya str. Tel.79166856098 isheiman@hse.ru_

igor.sheim@g23.relcom.ru_orcid 0000-0002-5238-4187

\section{References}

1. Early cancer diagnosis saves lives, cuts treatment costs. News release. WHO. February 3. 2017. Available from: https://www.who.int/news/item/03-02-2017-early-cancer-diagnosis-saves-lives-cutstreatment-costs.

2. OECD. Health at a Glance 2019: OECD Indicators. OECD Publishing, Paris. doi: https://doi.org/10.1787/4dd50c09-en.

3. Wilson JMG, Jungner G. Principles and practices of screening for disease. Geneva, Switzerland: World Health Organization; Public Health Papers. 1968;34. doi: http://whqlibdoc.who.int/php/WHO_PHP_34.pdf.

4. Prasad V, Lenzer J, Newman D. Why cancer screening has never been shown to 'save lives' and what we can do about it. BMJ. 2016;352:h6080. doi:https://doi.org/10.1136/bmj.h6080.

5. Mehrotra A, Zaslavsky AM, Ayanian JZ. Preventive Health Examinations and Preventive Gynecological Examinations in the United States. Arch Intern Med. 2007;167(17):1876-83. doi: 10.1001/archinte.167.17.1876.

Sep24

6. Gøtzsche PC. On the benefits and harms of screening for breast cancer. Int J Epidemiol. 2004 Feb;33(1):.56-64. doi:10.1093/ije/dyh014.

7. Sagan A, Rajan S, McDaid D, Farrington J, McKee M. Screening. When is it appropriate and how can we get it right? European Observatory on health systems and health reforms, Policy Brief. 2020;35;8.

8. Screening programmes. a short guide. Copenhagen: WHO Regional Office for Europe; 2020. 
9. McKee M, Rechel B. Screening. In: Rechel B, McKee M, editors. Facets of public health in Europe. WHO Observatory for health systems and health reforms. Open University Press; 2014.

10. Shishkin S. Russia's health care system: difficult path of reform. In: Weber S, Alexeev MV, editors. The Oxford Handbook of the Russian Economy. Oxford: Oxford University Press; 2013. doi:10.1093/oxfordhb/9780199759927.013.0025.

11. Skvorczova VI 'We are building a health system for each of 146 million people' [in Russian] Interview. Komsomolskaya Pravda. June 7, 2019. Available from: http://www.ffoms.ru/news/monitoringsmi/veronika-skvortsova-my-stroim-sistemu-zdravookhraneniya-dlya-kazhdogo-iz-146-781-095chelovek/.

12. Vergazova EK. The main priorities for the development of healthcare in Russia. Current requirements for the work of primary care physicians. [Russian] Presentation. The Ministry of Health of the Russian Federation. 2016. Available from: https://static0.minzdrav.gov.ru/system/attachments/attaches/000/029/345/original/Вергазова.pptx? 1456828556.

13. The Ministry of Health of the Russian Federation. On approval of the procedure for conducting a preventive medical examination and dispensarization of certain groups of the adult population. Order No. 124n, dated March 13, 2019. [Russian] http://publication.pravo.gov.ru/Document/View/0001201904250016.

14. Boitcov S. Prevention practice of noncommunicable diseases in the practice of a district doctor [in Russian] Presentation. National Research Center for Preventive Medicine; 2018.

15. The Ministry of Health of the Russian Federation. August, 12 2020. Available from: https://minzdrav.gov.ru/news/2020/08/12/14667-minzdrav-rossii-reglamentirovan-poryadok-vyplatmedikam-za-vyyavlenie-onkologicheskih-zabolevaniy-v-ramkah-dispanserizatsii-i-profosmotrov.

16. Rosstat, Health care in 2019 [Russian] Moscow. 2020. Available from: https://resursor.ru/statisticheskij-sbornik-zdravooxranenie-v-rossii-2019-polnaya-versiya/lechebnoprofilaktichesk-pomoshh-naseleniyu/\#1585774727290-407dfc70-a3d8.

17. Nolte E, Knai C, McKee M. Managing chronic conditions: experience in eight countries. World Health Organization. Regional Office for Europe. European Observatory on Health Systems and Policies, 2008. Available from: https://apps.who.int/iris/handle/10665/107920.

18. Round table 'Implementation of the activities of insurance representatives of insurance medical organizations' [in Russian] Mandatory Medical Insurance in the Russian Federation. 2018;3:4-11.

19. Medical information solutions. Report «Evaluation by the medical staff of outcome of the dispanserization (In Russian).

20. Federal Fund of Mandatory Health Insurance. Report about the mandatory health insurance system activity in the Russian Federation in 2019 [in Russian]. Mandatory Medical Insurance in the Russian Federation. 2020;4:22.

21. Reports on the activities. of the Ministry of Health of the Russian Federation in 2013 and 2019. 
22. Moscow Oncology Research Institute Moscow. 2020. Available from: https://glavonco.ru/cancer_register/Помощь 2019.pdf.

23. Sheiman I, Shevsky V. Concentration of health care providers: does it contribute to integration of service delivery? Risk Manag Healthc Policy. 2019 Aug 7;12:153-166. doi: 10.2147/RMHP.S205905.

24. Starodubov VI, Son IM, Senenko ASh, Savchenko ED, Dzyuba NA, Zakharchenko 00, Terentyeva DS. The outcomes of the clinical examination of certain groups of the adult population of the Russian Federation 2013-2018 [ Russian]. Moscow. 2019. Available from: https://elibrary.ru/item.asp? id=39409780.

25. Labour Code of the Russian Federation, No. 197-FZ dated December 30. 2001, amended by the Federal Laws No. 353-FZ dated October 3, 2018 and No. 261-FZ dated July 31, 2020 [in Russian]. Official Internet portal of legal information. Available from: http://pravo.gov.ru/proxy/ips/? docbody $=\&$ prevDoc $=102435144$ \&backlink $=1 \&$ nd $=102074279$.

26. Dispensarization in the. park: doctors of the Healthy Moscow pavilions - on the importance of regular examinations [in Russian]. Moscow Mayor official website. June 27, 2019. Available from: https://www.mos.ru/news/item/57780073/.

27. Rechel B. Financing of public health services. In: Rechel B, Jakubowski E, McKee M, Nolte E eds. Organization and financing of public health services in Europe. WHO. 2018.

28. Improving healthcare quality in Europe. Characteristics, effectiveness andimplementation of different strategies. Busse R, Klazinga N, Panteli D, Quentin W. eds. WHO Observatory on health systems and policies. 2019.

\section{Figures}




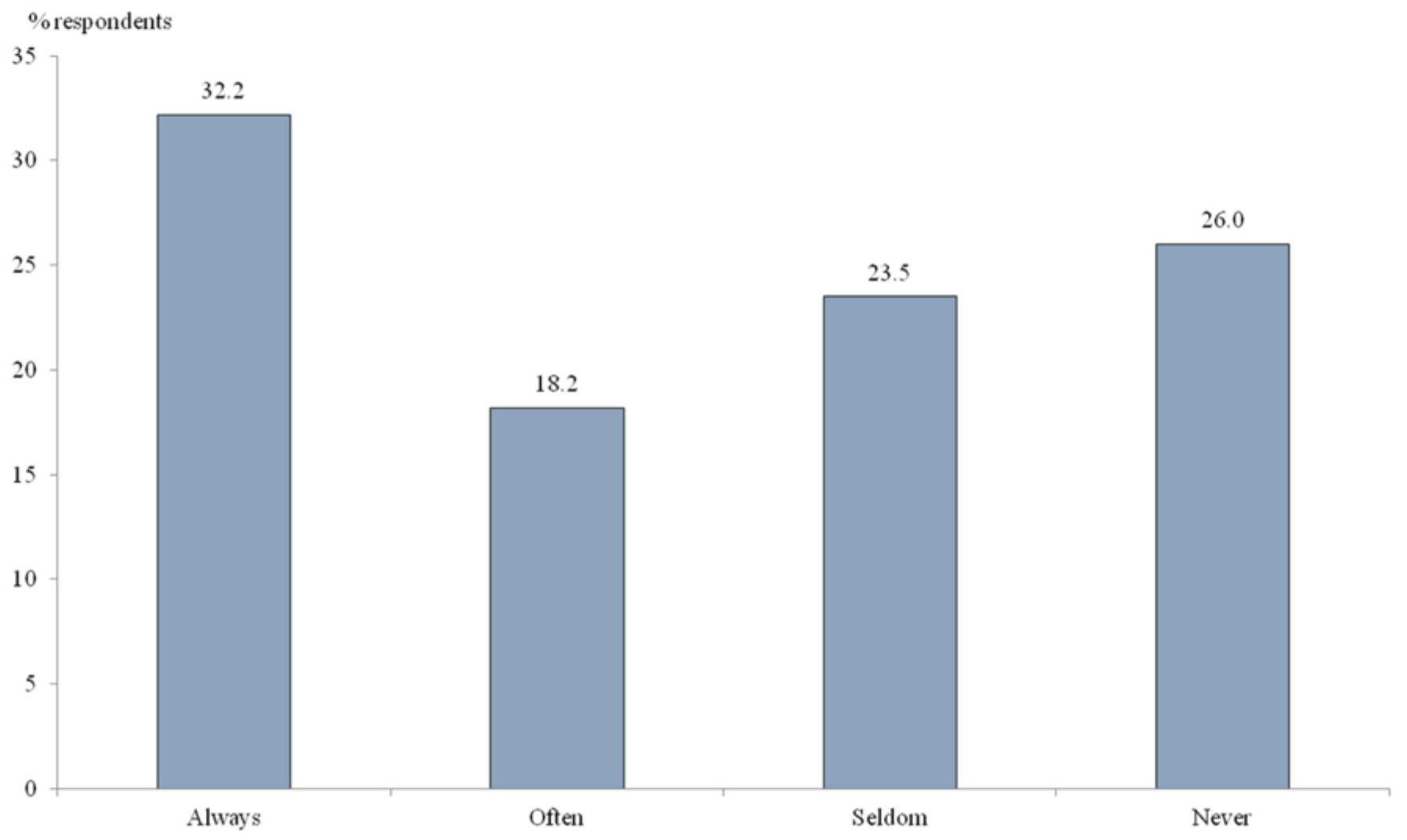

Figure 1

Distribution of responses to the question 'Do you receive information about results of medical examinations of your patients under the program of dispensarization when they are conducted by preventive units?' \% of all respondents 


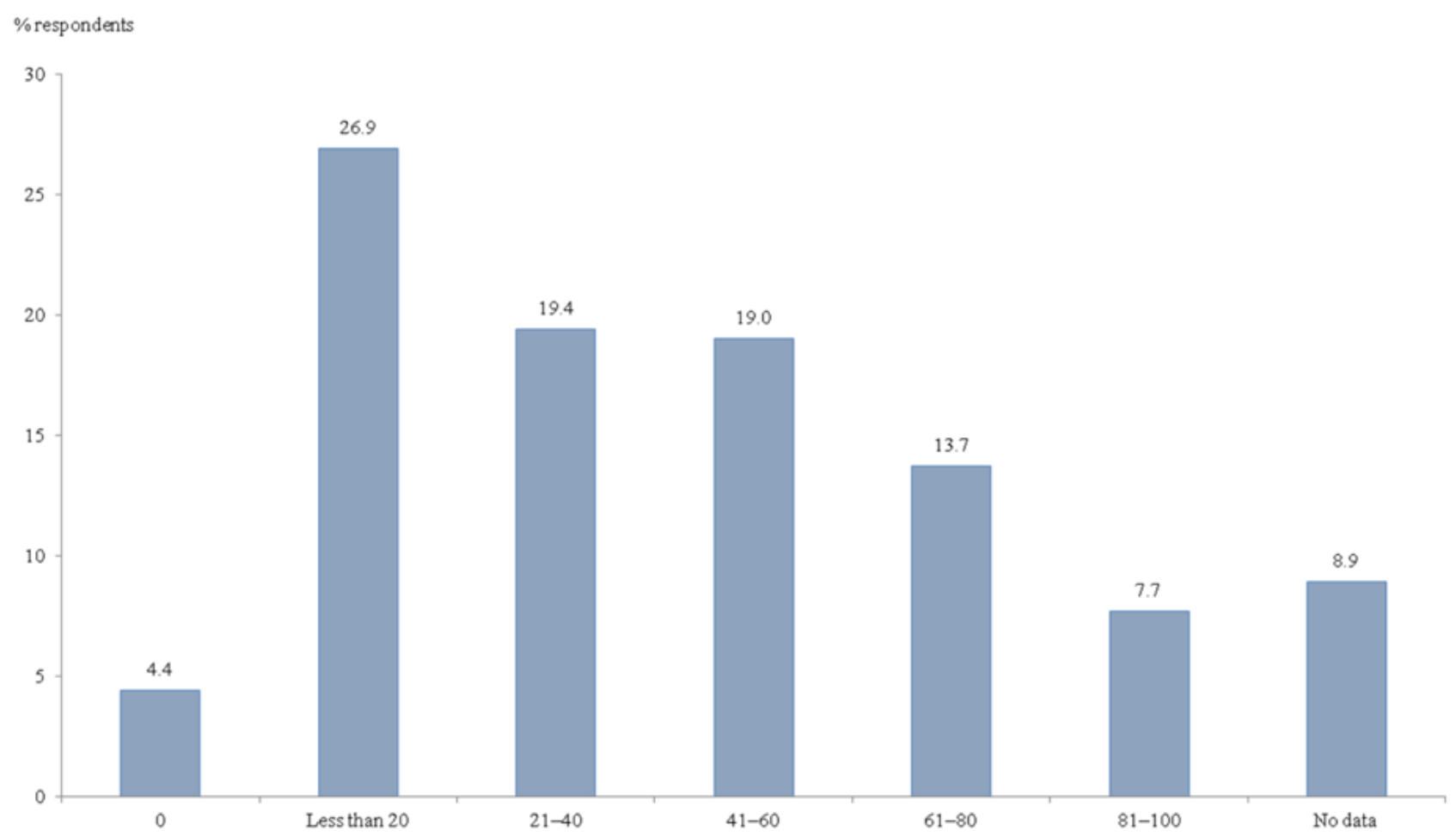

Figure 2. Distribution of responses to the question 'What is an approximate share of patients (who are assigned to a DP) is managed according to the requirements of the pattern of dispensary surveillance issued by the Ministry of Health?', \% of respondents

\section{Figure 2}

Please See image above for figure legend. 